\title{
Submucous fibrosis secondary to chewing of quids: another cause of unanticipated difficult intubation
}

\author{
[Une fibrose sous-muqueuse secondaire à la mastication de tabac : une autre cause \\ d'intubation difficile imprévue]
}

Rajesh Mahajan MD, Kajal Jain MD, Y.K. Batra MD MNAMS

Purpose: To report a case of unusual difficult intubation secondary to oral submucosal fibrosis (SMF) associated with malignancy of the hypopharynx.

Clinical features: A 57-yr-old male, ASA-I physical status presented for percutaneous nephrolithotripsy. The patient was a known alcoholic and smoker with a habit of chewing quids for the past 36 years. Airway assessment revealed oral SMF and slight difficulty in opening the mouth fully. Mentohyoid and mentothyroid distances were normal. However, during intubation, unanticipated difficulty was encountered. On direct laryngoscopy, the tip of the epiglottis could barely be visualized. Intubation was possible after passing a gum elastic bougie blindly under the epiglottis and negotiating a 7.0 internal diameter tracheal tube over it. Postoperatively, indirect laryngoscopy (IDL) showed severe SMF involving the oral cavity, epiglottis and pyriform fossae and an ulcerative malignancy of the hypopharynx with fixation of the left hemilarynx.

Conclusion: SMF is a premalignant condition of the oral cavity associated with fibrosis of involved structures that can be associated with malignancy of the aerodigestive tract. Distortion of the airway anatomy may render intubation difficult. IDL maybe useful in the preoperative evaluation of these patients.

Objectif : Citer un cas d'intubation difficile inhabituel secondaire à une fibrose sous-muqueuse buccale (FSM) associée à une condition maligne de l'hypopharynx.

Éléments cliniques : Un homme de 57 ans, d'état physique ASA I, a consulté pour une néphrolithotripsie percutanée. Connu pour alcoolisme et tabagisme, il chiquait du tabac depuis 36 ans. L'évaluation des voies respiratoires a révélé une FSM et une légère réduction de l'ouverture buccale. Les distances mento-hyoïde et mento-thyroïde étaient normales, mais l'intubation a présenté une dif- ficulté imprévue. Sous laryngoscopie directe, la pointe de l'épiglotte était à peine visible. L'intubation a été possible en passant à l'aveugle une bougie flexible sous l'épiglotte et en glissant par-dessus un tube endotrachéal de diamètre interne 7,0. La laryngoscopie indirecte (LID) postopératoire a montré une FSM sévère de la cavité buccale, l'épiglotte et les fosses piriformes, et une ulcération maligne de l'hypopharynx avec fixation de l'hémilarynx gauche.

Conclusion : La FSM est une condition maligne de la cavité buccale accompagnée de fibrose des structures concernées qui peut être associée à la malignité de la voie aéro-digestive. Une déformation anatomique des voies aériennes peut compliquer l'intubation. La LID peut faciliter l'évaluation préopératoire dans ces circonstances.

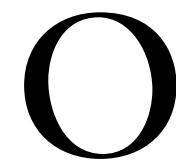

RAL submucous fibrosis (SMF) is a common condition in countries where betel nut is chewed habitually. It is characterized by the slowly progressive development of fibrous bands beneath the oral mucosa with secondary mucosal atrophy. It is widely accepted to be a collagen disease of insidious onset associated with chronic local irritation. Tongue movement is restricted and trismus may limit mouth opening. It is a precancerous condition and about one third of these patients develop oral cancer. ${ }^{1-3}$ We describe a patient with SMF who had an associated carcinoma of the hypopharynx, resulting in an unexpected difficult intubation.

Case history

A 57-yr-old male, ASA-I physical status, weighing 65 $\mathrm{kg}$ with a history of renal lithiasis was scheduled for

From the Department of Anaesthesia and Intensive Care Unit, Postgraduate Institute of Medical Education and Research (PGIMER ), Chandigarh, India.

Address correspondence to: Dr. Kajal Jain, Department of Anaesthesia and Intensive Care Unit, PGIMER, Chandigarh 160012, India.

Phone: 747585 ext. 206; E-mail: dr_kajal@hotmail.com

Accepted for publication September 27, 2001.

Revision accepted December 17, 2001.

CAN J ANESTH 2002/49:3/pp 309-311 
percutaneous nephrolithotripsy (PCNL). He was a known alcoholic and smoker for the past 36 years and had the habit of chewing quids composed of betel nut, lime and tobacco. His medical history was otherwise uneventful. The patient complained of mild dysphagia and a full throat sensation. His voice was slightly hoarse. Airway assessment revealed mild difficulty in opening the mouth fully. Mentohyoid and mentothyroid distances were normal. Mallampatti grading was II. Orodental hygiene was poor. The oral cavity showed blanched mucosa with fibrotic bands traversing the cheeks and soft palate suggestive of SMF. Cervical lymph nodes were normal. No difficulty in intubation was anticipated.

Anesthesia was induced with morphine $7.5 \mathrm{mg}$ and thiopentone $300 \mathrm{mg}$. Mask ventilation was possible and suxamethonium $100 \mathrm{mg}$ was given. On direct laryngoscopy the tip of the epiglottis could barely be visualized (Cormack and Lehane grade III). The epiglottis was thick, stiff and pale. Lifting of the epiglottis was virtually impossible. External laryngeal manipulation was attempted but failed to improve the field of vision. A gum elastic bougie was passed blindly underneath the epiglottis, into the trachea. A 7.0 internal diameter tracheal tube was then threaded into the trachea. Bilateral air entry was confirmed to be equal. Anesthesia proceeded uneventfully thereafter.

Since the preoperative airway assessment was normal, these findings were totally unanticipated. Postoperatively indirect laryngoscopy (IDL) showed atrophy of the papillae in the posterior part of the tongue. The pharyngeal mucosa was blanched and slightly opaque with a thickened epiglottis. There were ulceration and edema of the left arytenoid, medial wall of the pyriform fossa and lower part of the aryepiglottic fold with pooling of secretions in the left pyriform sinus. The left hemilarynx was fixed. A biopsy from the pyriform fossa showed squamous cell carcinoma. The rest of the hospital stay was uneventful. The patient was discharged on the seventh postoperative day and advised to come for further panendoscopic assessment.

\section{Discussion}

SMF is an oral condition reported mainly in the Indian subcontinent with a frequency of approximately $0.5 \%{ }^{1}$ Cases have also been reported in Taiwan, Thailand and UK. ${ }^{2,4,5}$

The disease begins with glossitis, stomatitis and vesicle formation. The hard palate, cheek, labial mucosa, tongue, faucillar pillars, soft palate and floor of the mouth can be involved. The condition is chronic and characterized clinically by blanching of the oral mucosa associated with mucosal inelasticity and stiffness. Mobility of the tongue may be decreased. The faucillar pillars may become thick and short. Sometimes the condition spreads to the pharynx and down to the pyriform fossae. In severe cases, the patient may have difficulty in chewing, swallowing and speaking. Paymaster first noted the development of oral cancer in about one third of these patients, ${ }^{6}$ and Pindborg subsequently pointed out the precancerous nature of this condition. ${ }^{3}$ In addition to chewing tobacco and betel nuts, tobacco smoking and alcohol consumption have also been acknowledged as a cause of oral premalignant and malignant changes. ${ }^{7}$

SMF forms at the back of the mouth and progresses forward as the severity of the disease increases. Moreover the location of bands in a patient with oral SMF is related to the way in which areca nut is chewed. ${ }^{8}$ Absence of trismus, therefore, does not necessarily exclude involvement of the back of the mouth and pharynx. So one may face an unanticipated difficult airway in patients with SMF, irrespective of the degree of mouth opening.

Allen and Osman previously reported a case of SMF in the anesthetic literature. ${ }^{9}$ The patient had complete trismus and elective fibreoptic intubation was done. It is essential to have proper preoperative preparation in such cases with anticipated difficulty airway. Awake intubation, blind oral or nasotracheal technique, retrograde intubation, illumination stylet and fibreoptic intubation can be used. ${ }^{10}$

In our patient difficulty in laryngoscopy was totally unanticipated. The patient had ill defined symptoms of dysphagia and hoarseness of voice, but since most smokers and alcoholics suffer from chronic laryngitis, we did not suspect malignant changes. ${ }^{1}$ On induction of anesthesia, mask ventilation was possible. General anesthesia with spontaneous ventilation and a face mask could have been an alternative if surgery had been of shorter duration with the patient in a supine or lateral position. However, this was not an option in this case. The laryngeal mask airway (LMA) is a good option in such cases and has been used as a conduit for fibreoptic tracheal intubation. ${ }^{12}$ Although successful use of LMA as a ventilatory device has been reported in the prone position, it can be associated with regurgitation, displacement and airway obstruction. ${ }^{13-16}$

Neuraxial blockade may be the preferred alternative wherever the surgical procedure allows for it. Since, PCNL is carried out in the prone position, regional anesthesia in such patients is not a routine practice in our centre.

In addition to fibrosis of the involved structures which can distort the airway anatomy, SMF may be 
associated with malignancy of the aerodigestive tract. These changes may lead to difficult airway manipulation. However, if IDL had been performed prior to the surgical procedure, it would have not only defined the extent of SMF in our patient, but could have diagnosed also the malignant changes in the hypopharynx, thereby suggesting a difficult intubation.

In summary, we encountered a difficult intubation in a patient with SMF and an otherwise unremarkable preoperative airway examination. Intubation difficulties were related to fibrosis secondary to SMF and to the presence of unsuspected upper airway malignancy. IDL, a readily accessible and simple bedside examination, may be useful in the preoperative evaluation of these patients.

\section{References}

1 Pindborg JJ, Chawla TN, Srivastava AN, Gupta D, Mehrotra ML. Clinical aspects of oral submucous fibrosis. Acta Odontol Scand 1964; 22: 679-91.

2 Su I-P. Idiopathic scleroderma of the mouth. Report of three cases. Arch Otolaryngol 1954; 59: 330-4.

3 Pindborg JJ. Is submucous fibrosis a precancerous condition in the oral cavity? Int Dent J 1972; 22: 474-80.

4 Reichart PA, Khongkhunthian P, Scheifele C, Lobsuwan $P$. Thai dental student's knowledge of the betel quid chewing habit in Thailand. Eur J Dent Educ 1999; 3: 126-32.

5 Farrand P, Rowe RM, Johnston A, Murdoch $H$ Prevalence, age of onset and demographic relationships of different areca nut habits amongst children in Tower Hamlets, London. Br Dent J 2001; 190: 150-4.

6 Paymaster JC. Cancer of the buccal mucosa: a clinical study of 650 cases in Indian patients. Cancer 1956; 9: 431-5.

7 Gluckman JL, Savoury LW. Carcinoma of the oral cavity. In: Paparella MM, Shumrick DA (Eds.). Otolaryngology, $3^{\text {rd }}$ ed. Philadelphia: WB Saunders, 1991: 2041-67.

8 Haider SM, Merchant AT, Fikree FF, Rabbar MH. Clinical and functional staging of oral submucous fibrosis. Br J Oral and Maxillofac Surg 2000; 38: 12-5.

9 Allen PW, Osman HG. Submucous fibrosis (Letter). Anaesthesia 1988; 43: 809-10.

10 Caplan RA, Benumof JL, Berry FA, et al. Practice guidelines for management of the difficult airway. A report by the American Society of Anesthesiologists Task Force on management of the difficult airway. Anesthesiology 1993; 78: 597-602.

11 Harrison DFN. Tumors of the hypopharynx. In: Paparella MM, Shumrick DA (Eds.). Otolaryngology, $3^{\text {rd }}$ ed. Philadelphia: WB Saunders, 1991: 2199-214.

12 Benumof JL. Laryngeal mass airway and the ASA diffi- cult airway algorithm. Anesthesiology 1996; 84: 686-99.

13 Malligan KA. Laryngeal mask in the prone position (Letter). Anaesthesia 1994; 49: 449.

14 Herrick MJ, Kennedy DJ. Airway obstruction and the laryngeal mask airway in paediatric radiotherapy (Letter). Anaesthesia 1992; 47: 910.

15 Lim W, Cone AM. Laryngeal mask and the prone position (Letter). Anaesthesia 1994; 49: 542.

16 Fisher JA, Ananthanarayan C, Edelist $G$ Role of the laryngeal mask in airway management (Editorial). Can J Anaesth 1992; 39: 1-3. 